\title{
Reducing Urban Heat Island Effects While Providing Affordable Housing in Bunker Hill
}

Kathryn F. Atherton ${ }^{1,2,3}$, Vrinda Dambal ${ }^{3,4}$, Tara K. Miller $^{2,3,5}$, Ian A. Smith ${ }^{2,6}$, Jessica Wright ${ }^{2,3,5}$

1Bioinformatics Program, Boston University, Boston, MA

${ }^{2}$ Graduate Program in Urban Biogeoscience and Environmental Health, Boston University, Boston, MA

${ }^{3}$ Science and Technology in Public Policy at Boston University

4Program in Biomedical Sciences, Graduate Medical Sciences, Boston University School of Medicine, Boston, MA

${ }^{5}$ Biology Department, Boston University, Boston, MA

${ }^{6}$ Earth \& Environment Department, Boston University, Boston, MA

https://doi.org/10.38126/ISPG180404

Corresponding Author: jwright9@bu.edu

Keywords: Climate mitigation; cool roofs; ecosystem services; environmental justice; low-income housing; public health; urban heat island

Executive Summary: The Bunker Hill Public Housing development is a historic public housing building, home to a large population of racial and ethnic minorities, that requires major redevelopment and repair to enhance the safety of its residents. The Boston Planning and Development Agency (BPDA) recently approved a $\$ 1.46$ billion redevelopment for the property, a part of which is allocated to remove and replace $\sim 250$ mature trees around the public housing units. Removal of these trees would affect an already vulnerable population significantly more exposed to the effects of heat events, including heat-related stress, morbidity, and mortality, which will worsen with climate change in the coming years. While the BPDA proposal seeks to address the issue that the area already experiences $20 \%$ less cooling due to a lack of vegetation by replanting more trees, their estimated timescale of more than a decade for the canopy to just return to its current size is concerning. In order to mitigate the added heat stress caused by the tree removal, we propose the supplementary action of installing green roofs on buildings throughout the development. These green roofs would continue to provide cooling and beneficial community services even once the tree canopy has returned. These measures will serve as an appropriate stopgap measure until the canopy can return to size and expand as well as providing the community with the same co-benefits, such as air quality improvement, noise pollution reduction, community spaces, and locally grown food from community gardens, that more affluent parts of the city already experience. The installation of green roofs and supplemental vegetation will take only $0.25 \%$ of the entire redevelopment project budget and will have a large return in community wellness.

I. The Bunker Hill community and public housing development

The Bunker Hill Public Housing development is located in Charlestown, MA, one of Boston's oldest neighborhoods. While Charlestown is an affluent and predominantly white neighborhood, the residents of the public housing development are a low-income and predominantly racial and ethnic minority community (Figure 1).

The Bunker Hill Public Housing development is one of the oldest such developments in the country, built in 1940, and the largest in Boston (Greeley et al. 2021). The existing buildings have a number of 


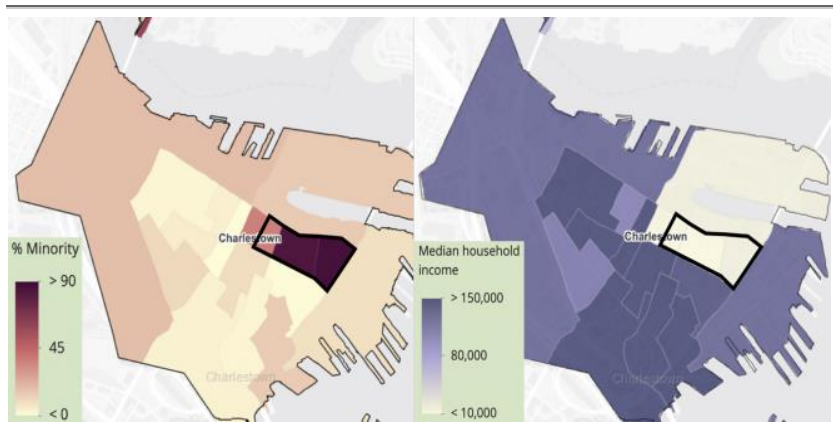

Figure 1: Map of Charlestown, MA showing (left) percent minority population by census block group and (right) average household income per block group (Jiminez Celsi 2020). The public housing development is outlined in the black line.

health hazards, including mold and asbestos (Greeley et al. 2021). The city is working to renovate the area in order to improve the living conditions for the residents. The plans include construction of energy-efficient and environmentally friendly buildings (Greeley et al. 2021). The project includes plans to demolish the existing 1,100-unit Boston Housing Authority site and build 2,699 new, mixed-income residential units in eleven construction phases over the next ten to fifteen years (Bunker Hill GP Venture LLC. 2021).

\section{Boston's Climate Action Plan and Bunker Hill's tree canopy}

The City of Boston has outlined a Climate Action Plan that includes the expansion of its urban forest, especially focused on protecting and expanding tree canopies in communities most vulnerable to environmental stressors (Department of Parks and Recreation 2021). The new Bunker Hill Public Housing buildings will contribute to Boston's 2019 Climate Action Plan goals of transitioning to zeronet carbon new construction through energy savings and electrification of building systems and will improve air quality and comfort for residents (Greeley et al. 2021). However, the BPDA plans to remove two-thirds of the healthy trees in the area during construction to make way for the new infrastructure (Greeley et al. 2021), which runs counter to the goals of the Climate Action Plan.

The existing cooling effects provided by vegetation in Bunker Hill are already about 20\% less than the average cooling from vegetation across Boston, while the demand for cooling by the Bunker Hill Public Housing community is 3.5 times greater than the average across Boston (Figure 2). The Bunker Hill community is significantly more vulnerable to the effects of heat events, including heat-related stress, morbidity, and mortality, which will worsen with climate change in the coming years (Hondula et al. 2015). The healthy trees cool the area and remove pollution; removing them will exacerbate the discrepancy in the supply and demand for vegetative cooling for this community until the canopy grows back to its current size. While 500 new trees will be planted over the course of the redevelopment initiative

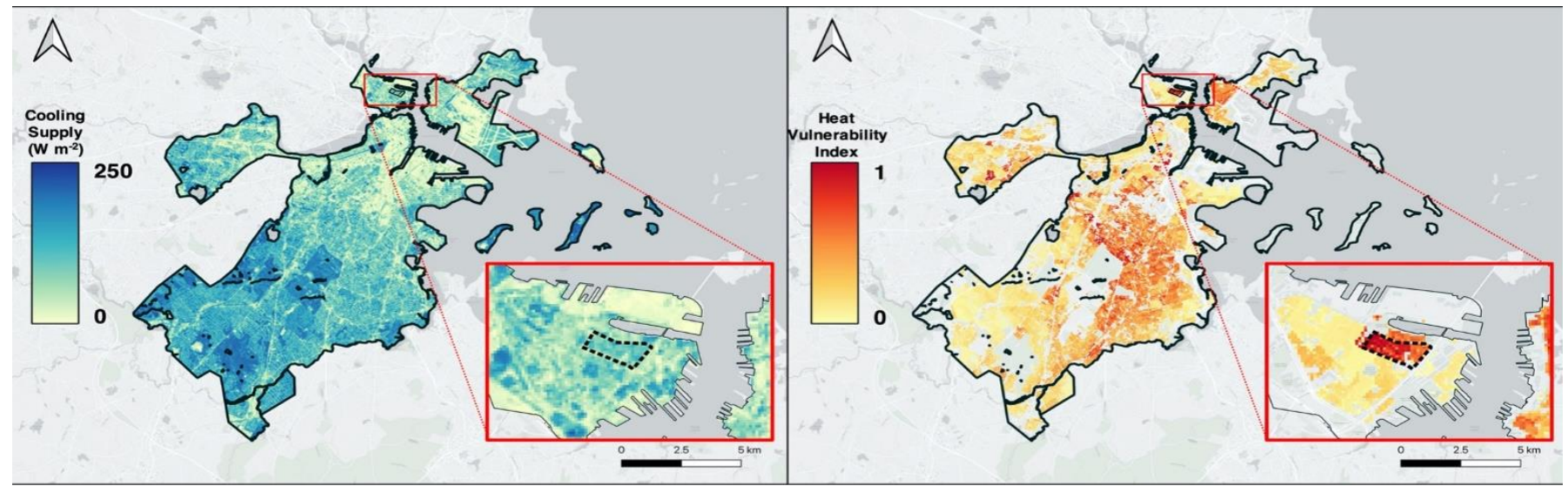

Figure 2: Maps of the City of Boston, with the Bunker Hill Public Housing community identified by the black, dashed polygon in the map insets. The map on the left shows the average summertime midday cooling supply provided by evapotranspiration from the existing tree canopy, with dark blue regions providing more cooling than yellow regions. The right is a map of heat vulnerability, as estimated by the likelihood of experiencing a heatwave day, the population density, and sociodemographic characteristics (specifically a function of age, race, income, language, and vulnerable living situation). The Bunker Hill Public Housing community experiences a below-average cooling supply and high heat vulnerability from the existing canopy (Tieskens et al. in review). 
(Greeley et al. 2021), the majority of the cooling effects from the vegetation will be lost while the new trees grow back to the current canopy size. The BPDA expects that the re-growth period will take ten years after each phase of construction, while studies of urban tree mortality indicate that it may take even longer (Smith et al. 2019; Roman 2014).

The approved removal of mature trees for the redevelopment of the public housing development in Charlestown is concerning for the community and does not align with the climate action goals outlined in the City of Boston's urban canopy plan. The Charlestown community has made public comments to remind the BPDA of the urban tree canopy goals, emphasizing their local experience with intense heat stress due to a reduced urban canopy (Duverge 2020). To address residents' concerns, the current plans for the Bunker Hill Housing Redevelopment suggest the use of "cool roofs", but they do not specify what form these will take. Here, we present two different options for heat mitigation using roof infrastructure and discuss the consequences of failing to successfully implement cool roofs.

\section{Policy options}

In order to mitigate the added heat stress caused by tree removal, we propose the supplementary action of installing green roofs on buildings throughout the development. Outlined below are policy options to help alleviate the environmental and public health stressors associated with the removal of these mature trees.

\section{i. Option 1: Install green roofs}

To mitigate urban heat island effects for residents, apartments, and surrounding neighborhoods, vegetation-including rooftop gardens-can be installed on roofs. This works through evaporative cooling, i.e., the loss of heat through the evaporation of water from plants and other surfaces (Sharma et al. 2016). Green roofs can result in 12 to $15^{\circ} \mathrm{F}$ cooler air temperatures (Sharma et al. 2016).

\section{Advantages}

Installing green roofs cools the area in the summer and provides insulation in the winter. As such, green roofs can reduce building energy consumption by up to $0.7 \%$, which leads to an annual savings of $\$ 0.27$ per square foot of the roof's surface (Sailor 2011). We calculate that of the entire twenty-six-acre area for the project (Greeley et al. 2021), seven acres will be roof space. We additionally estimate that only five acres of the roof space will be available for green roof infrastructure, to allow for walkways between plants. Therefore, we expect that a green roof will save all tenants a total of nearly $\$ 60,000$ per year in electricity costs.

Green roofs provide a pleasant green space that can benefit the well-being of residents. The direct benefits of green roofs include improving air quality, and thus resident health (Sharma et al. 2016), enhancing water quality and lowering management costs by reducing stormwater runoff (Niu et al. 2010), promoting local biodiversity (Brenneisen 2003), and providing residents the benefits of exercise, healthy food, and fostering community and social cohesion (Kabisch 2017; Shafique 2018). In addition, green roofs can reduce road traffic noise by 2.3 to 5.5 decibels (Van Renterghem 2017), addressing resident concerns about noise pollution from Tobin Bridge (Duverge 2020). The rooftops of the Bunker Hill Public Housing may be able to provide vegetables for around 2,000 residents (Orsini et al. 2014). Additionally, green roof space can be used as a living classroom for environmental education.

Recently, a bill was introduced by Rep. Nydia M. Velázquez in New York which focuses on implementing green roofs at public elementary and secondary schools (Office of Congresswoman Nydia M. Velázquez 2021). The bill was introduced following up on its success in other states in addition to a successful installation of green roofs on an elementary school in Greenwich village, a densely populated area of New York city. This 9,000-square-foot installation produced a $32 \%$ reduction in greenhouse emissions, a $27.8 \%$ reduction in energy consumption, and sequestration of around 182,250 gallons of stormwater annually (GreenRoofs.com, LLC 2021). In addition, the average life expectancy of a green roof is forty years as compared to seventeen years for a conventional roof. These added benefits and the durability of green roofs make it the most effective and beneficial choice (Massachusetts 
Department of Environmental Protection 2021; United States General Service Administration 2011).

\section{Disadvantages}

This option is more expensive and requires more infrastructure and maintenance compared to white roofs. Green roofs can range from $\$ 15$ to $\$ 20$ per square foot (Low Impact Design Center, Inc. 2007). As previously stated, we calculate that of the entire twenty-six-acre area for the project (Greeley et al. 2021), five acres of the roof space will be available for green roof infrastructure. At an estimated cost of $\$ 17$ per square foot, green roofs will cost an additional $\$ 3,702,600$ to this project, increasing the current budget by $0.25 \%$.

\section{ii. Option 2: Paint the roofs white}

In order to keep the apartments and surrounding areas cooler, the roofs of buildings can be painted white. This works to cool the area by reflecting a greater amount of solar radiation than a darker roof would (Sharma et al. 2016). In a study of newly implemented white roofs in East Boston, Boston University researcher Ian Smith found that white roofs nearly doubled the amount of solar radiation reflected away from the surface compared to the previously existing land cover (Smith 2021). White roofs can result in 13 to $18^{\circ} \mathrm{F}$ cooler air temperatures (Sharma et al. 2016).

\section{Advantages}

This option works to cool the area, leading to a $\$ 0.11$ per square foot savings in annual cooling costs (Konopacki and Akbari 2001). We estimate that of the entire twenty-six-acre area for the project, seven acres will be roof space that can be painted white. This would reduce the annual cooling costs of the building by $\$ 33,541$. Additionally, white roofs are relatively inexpensive, ranging from $\$ 0.75$ to $\$ 1.50$ per square foot (United States Environmental Protection Agency n.d.). At an estimated cost of $\$ 1$ per square foot, white roofs would cost $\$ 304,920$, increasing the current budget by $0.02 \%$.

\section{Disadvantages}

White roofs lack the winter insulation provided by green roofs, leading to an average annual heating penalty cost of $\$ 0.56$ per square foot of roof (an estimated $\$ 170,755$ in this case), which does not outweigh the cooling savings (United States Environmental Protection Agency n.d.). Additionally, the social equity, noise dampening, health, well-being, food source, green space, and community space advantages of green roofs are not available on white roofs.

\section{Consequences of inaction}

As the redevelopment plan exists, the removal of nearly 250 mature trees without proper action to mitigate the impacts of the removal will be detrimental to the health of the residents and is not in line with the City of Boston's Climate Action Plan (Department of Parks and Recreation). The loss of these trees, without mitigation actions, means the loss of the crucial ecosystem services provided to the residents living in the public housing development. The services of urban trees include the mitigation of excess heat from shade and vegetative cooling, increasing recreational activity, increasing biodiversity, decreasing stormwater runoff and flooding, sequestering carbon, and producing a variety of public health benefits (Jenerette et al. 2011). Of special concern for the Bunker Hill Public Housing development is the vegetative cooling provided by the existing tree canopy. Vegetative cooling is already lower in the area, as compared to surrounding neighborhoods (Figure 2), and without action to cool the area upon the removal of the trees, residents are likely to experience disproportionately high heat-related health effects (Schmeltz et al. 2016), with significant consequences for both residents and costs incurred to Boston's healthcare system. An increase in vegetative cooling has the potential not only to reduce excess heat and heat-related health outcomes but also to lower annual energy costs by nearly $\$ 60,000$, saving the development and its residents money in the future (Sailor 2011). Ecosystem services from urban trees are an integral part of the health of an urban community and need to be maintained through green roofs and other technologies to improve the life and health of residents. Therefore, the consequences of removing the trees without proper mitigation action should be understood and cannot be overlooked in the planning process.

\section{Policy recommendation}

We recommend implementing green roofs for the purpose of heat reduction, with the additional 
benefits of providing many important services for the community, including benefits for health, equity, and recreation. If the cost of green roofs

\section{References}

Brenneisen, S. "The benefits of biodiversity from green roofs - key design consequences." Proceedings from greening rooftops for sustainable communities, first North American green roof infrastructure conference. May 29 and 30, Chicago, 2003.

Bunker Hill GP Venture LLC. "One Charlestown Environmental Notification Form / Expanded Project Notification Form." Boston, MA: Boston Planning and Development Agency, 2021. https://bpda.app.box.com/s/i9j5ybypggj0do4 6900iutsg73k689ok.

Department of Parks and Recreation. "City of Boston Seeks Partner to Design First Urban Forest Plan." City of Boston, March 21, 2021. https://www.boston.gov/news/city-bostonseeks-partner-design-first-urban-forest-plan.

Duverge, Raul. "Bunker Hill Housing Redevelopment Public Comments." Boston, MA: Boston Planning and Development Agency, 2020. https://bpda.app.box.com/s/lqvd597srbhe4vr zkvl1h7zhhh7s0twf.

Greeley, Jonathan, Michael Christopher, Raul Duverge, Christopher Breen, Alexa Pinard, Jill Zick, Ted Schwartzberg. "Bunker Hill Housing Redevelopment, Charlestown." Official memorandum. Boston, MA: Boston Planning and Development Agency, 2021.

https://bpda.app.box.com/s/q64rgscmdmu0c 1cuy9s5dktji9v3p7op.

GreenRoofs.com, LLC. "New York PS41 greenroof environmental literacy laboratory (GELL)," 2021.

https://www.greenroofs.com/projects/newyork-ps41-greenroof-environmental-literacylaboratory-gell/.

Hondula, David M., Robert E. Davis, Michael V. Saha, Carleigh R. Wegner, Lindsay M. Veazey. "Geographic dimensions of heat-related mortality in seven U.S. cities." Environmental Research, 138 (April 2015): 439-452. https://doi.org/10.1016/i.envres.2015.02.033.

Jenerette, G. Darrel, Sharon L. Harlan, William L. Stefanov, Chris A. Martin. "Ecosystem services and urban heat riskscape moderation: water, green spaces, and social inequality in Phoenix, USA." Ecological Applications, 21, no. 7 (Oct 2011): 2637-2651.

https://doi.org/10.1890/10-1493.1. makes this option unfeasible, we recommend white roofs, as they are less expensive and still provide similar cooling benefits (Li 2014).

Jimenez Celsi, Raquel. "Exploring Tree Equity in Boston." bucas.maps.arcgis.com. Speak for the Trees Boston, 2020.

https://bucas.maps.arcgis.com/apps/MapSeri es/index.html?appid=34e653bf29e64b72a64e 78a175732b34.

Kabisch, Nadja, Matilda van der Bosch, Raffaele Lafortezza. "The health benefits of naturebased solutions to urbanization challenges for children and the elderly - a systematic review." Environmental Research, 159 (Nov 2017):362373. https://doi.org/10.1016/i.envres.2017.08.004.

Konopacki, Steven J, and Akbari, Hashem. Mon . "Measured energy savings and demand reduction from a reflective roof membrane on a large retail store in Austin". United States. https://doi.org/10.2172/787107.

Li, D., E. Bou-Zeid, M. Oppenheimer. "The effectiveness of cool and green roofs as urban heat island mitigation strategies." Environmental Research Letters, 9, (2014): 055022. https://doi.org/10.1088/17489326\%2F9\%2F5\%2F055002.

Low Impact Design Center, Inc. "Green Roofs: Costs." 2007.

http://www.lidstormwater.net/greenroofs cost.htm.

Massachusetts Department of Environmental Protection. "Green roofs \& stormwater management.," 2021.

https://www.mass.gov/service-details/greenroofs-stormwater-management.

Niu, H., C. Clark, J. Zhou, P. Adriaens. "Scaling of economic benefits of green roof implementation in Washington, DC." Environmental Science \& Technology, 44, no. 11 (2010):4302-4308. https://doi.org/10.1021/es902456x.

Office of Congresswoman Nydia M. Velázquez. "Velázquez reintroduces bill to bring green rooftops to public schools." March 2021. https://velazquez.house.gov/mediacenter/press-releases/velazquezreintroduces-bill-bring-green-rooftops-publicschools. 
Orsini, Francesco, Daniela Gasperi, Livia Marchetti, Chiara Piovene, Stefano Draghetti, Solange Ramazzotti, Giovanni Bazzocchi, Giorginio Gianquinto. "Exploring the production capacity of rooftop gardens (RTGs) in urban agriculture: the potential impact on food and nutrition security, biodiversity and other ecosystem services in the city of Bologna." Food Security, 6, no. 6 (October 2014):781-792. https://doi.org/10.1007/s12571-014-0389-6.

Roman, Lara A. "How Many Trees Are Enough? Tree Death And The Urban Canopy." Scenario Journal, Scenario 04: Building the Urban Forest, (Spring 2014).

https://scenariojournal.com/article/howmany-trees-are-enough.

Sailor, David J., Timothy B. Elley, and Max Gibson. "Exploring the Building Energy Impacts of Green Roof Design Decisions - a Modeling Study of Buildings in Four Distinct Climates." Journal of Building Physics 35, no. 4 (2011): 372-91. https://doi.org/10.1177/1744259111420076.

Schmeltz, Michael T., Elisaveta P. Petkova, Janet L. Gamble. "Economic Burden of Hospitalizations for Heat-Related Illnesses in the United States, 2001-2010." International Journal of Environmental Research and Public Health, 13, no. 9 (Sept 2016): 894. https://dx.doi.org/10.3390\%2Fijerph1309089 $\underline{4}$.

Shafique, M. R. Kim, M. Rafiq. "Green roof benefits, opportunities, and challenges - A review." Renewable and sustainable energy review, 90 (2018):757-773.

http://doi.org/10.1016/i.rser.2018.04.006.
Sharma, A., P. Conry, H.J.S. Fernando, A.F. Hamlet, J.J. Hellmann, F. Chen. "Green and cool roofs to mitigate urban heat island effects in the Chicago metropolitan area: evaluation with a regional climate model." Environmental Research Letters, 11, (June 2016): 064004. https://doi.org/10.1088/17489326/11/6/064004.

Department of Parks and Recreation. "City of Boston Seeks Partner to Design First Urban Forest Plan." City of Boston, March 21, 2021. https://www.boston.gov/news/city-bostonseeks-partner-design-first-urban-forest-plan.

Smith, Ian A. "Heat vulnerability index" Unpublished data, 2021.

Smith, Ian A., Victoria K. Dearborn, Lucy R. Hutyra. "Live fast, die young: Accelerated growth, mortality, and turnover in street trees." PLOS ONE, 14, no. 5 (May 2019): e0215846. https://doi.org/10.1371/journal.pone.021584 6.

Tieskens, K.F., Smith, I.A., Jimenez Celsi, R.B., Hutyra, L.R., Fabian, M.P. "Mapping the cooling health benefits of greenspace through an ecosystem services framework." In review.

United States General Service Administration. "The benefits and challenges of green roofs on public and commercial buildings: A Report of the United States General Service Administration," 2011.

https://www.gsa.gov/cdnstatic/The Benefits and Challenges of Green Roofs on Public and Commercial Buildings.pdf.

United States Environmental Protection Agency. "Using Cool Roofs to Reduce Heat Islands." n.d. https://www.epa.gov/heatislands/using-coolroofs-reduce-heat-islands.

Van Renterghem, T. "Green roofs for noise reduction: literature review and new approaches." (2017).

Kathryn F. Atherton is a Ph.D. candidate in bioinformatics at Boston University. She studies how the soil microbiome impacts tree health along an urban-to-rural gradient. In addition to her research, Kathryn is the secretary of Science and Technology in Public Policy (STEPUP) at Boston University and the Bioinformatics Program student organization. She is a member of the National Science Policy Network.

Vrinda Dambal is a Ph.D. candidate in Biomedical Sciences at Boston University. She studies the role of oxidative stress in pulmonary arterial hypertension. She is a member of the National Science Policy Network (NSPN) and Science and Technology in Public Policy (STEPUP) at Boston University.

Tara K. Miller is a Ph.D. candidate in Biology at Boston University. Ze studies the effects of climate change on plants and wildlife in North America, using herbarium specimens and wildlife rehabilitation records. Ze is the president of Science and Technology in Public Policy (STEPUP) at Boston University and a member of the National Science Policy Network (NSPN). 
Ian A. Smith is a Ph.D. candidate in Earth and Environment at Boston University. He studies energy and mass transfer between the land surface and atmosphere in urban ecosystems with a focus on strengthening climate adaptation strategies.

Jessica Wright is a Ph.D. candidate in Earth and Environment at Boston University. She studies urban infrastructure dynamics and urban climate action plans to inform energy transition across Massachusetts. She is a trainee in the BU URBAN program and the vice president of STPEUP (Science and Technology in Public Policy) at Boston University.

\section{Acknowledgements}

The authors would like to thank Stephen Decina for his edits and feedback during the development of the memo as well as Raquel Jimenez Celsi and Koen Tieskens for allowing us to use their data in our figures. 